\title{
Administration of oxytocin antagonist at the same time as using a Foley catheter with cotton swab before embryo transfer for cervical stenosis
}

Heesuk Chae* ${ }^{*}$

\begin{abstract}
Background: Embryo transfer without difficulty in a patient with cervical stenosis can be a great challenge for in vitro fertilization (IVF). We report a successful pregnancy following a frozen thawed embryo transfer after administration of an oxytocin antagonist at the same time as using a Foley catheter with cotton swab in a patient with refractory cervical stenosis.
\end{abstract}

Case presentation: A 40-year-old woman undergoing IVF. The patient's previous embryo transfers were difficult. For every transfer, uterine manipulation was needed, force was required, and dilatation was necessary. A Foley catheter with a cotton swab was inserted into the cervical canal, atosiban was administered at the same time, and the Foley catheter was removed immediately before embryo transfer. A smooth transfer was performed without bleeding, force, uterine manipulation, or cervical dilator. The patient became pregnant and delivered by cesarean section at term.

Conclusion: This method is effective in performing atraumatic embryo transfer in patients with cervical stenosis.

Keywords: Embryo transfer, Cervical stenosis, Foley catheter, Atosiban

\section{Background}

The embryo transfer (ET) without difficulty has been recognized as one of the most critical factors in the success of in vitro fertilization (IVF) cycles. A difficult transfer usually result in bleeding with multiple attempts and, in more difficult cases, even cervical dilators can be used. Blood on the outside of the catheter at the time of ET and multiple attempts of catheter entry have been associated with decreased pregnancy rates [1]. ET using additional maneuvers such as tenaculum has been shown to progressively decrease pregnancy rate [2]. In the end,

\footnotetext{
*Correspondence: hschae@jbnu.ac.kr

Department of Obstetrics and Gynecology, Research Institute of Clinical Medicine of Jeonbuk National University, Biomedical Research Institute of Jeonbuk National University Hospital, Jeonbuk National University, 20, Geonji-ro, Deokjin-gu, Jeonju-si, Jeollabuk-do 561-712, South Korea
}

atraumatic transfer technique in a patient with cervical stenosis can be a great challenge for IVF.

The present case report describes a successful pregnancy following a frozen thawed embryo transfer after administration of oxytocin antagonist at the same time as using a Foley catheter with cotton swab in a patient with refractory cervical stenosis.

\section{Case presentation}

The patient is a 40 -year-old, gravida 0 , para 0 , who presented with two years of infertility. The patient was diagnosed with type 2 diabetes mellitus at the age of 20 and is currently taking medication. She had a history of laparoscopic myomectomy a year ago. Menstrual cycles had been regular with normal flow. Transvaginal ultrasonography showed that the anteverted and anteflexed 
uterus and both ovaries were normal. Baseline hormonal assays showed the following: follicle stimulating hormone (FSH) $7.2 \mathrm{mIU} / \mathrm{mL}$, luteinizing hormone (LH) $11.5 \mathrm{mIU} / \mathrm{mL}$, estradiol $\left(\mathrm{E}_{2}\right) 30.4 \mathrm{pg} / \mathrm{mL}$, progesterone (P) $0.35 \mathrm{ng} / \mathrm{mL}$. Serum anti-Müllerian hormone $(\mathrm{AMH})$ level was $4.1 \mathrm{ng} / \mathrm{mL}$. The hysterosalpingography (HSG) and semen analysis were unremarkable. She had received several cycles of timed intercourse at local clinic before coming here and two cycles of ovulation induction with clomiphene citrate at our clinic, but all failed. After counseling, she was scheduled for a long protocol of down-regulation using gonadotropinreleasing hormone (GnRH) agonist. For oocyte maturation, human chorionic gonadotropin (hCG) was given when the leading follicle was more than $18 \mathrm{~mm}$. Nineteen oocytes were retrieved by an ultrasonic-guided transvaginal route $36 \mathrm{~h}$ later, of which 11 fertilized. After filling the bladder, a clear line from the cervix to the endometrium was confirmed by ultrasound. Embryo transfer was attempted using a Wallace catheter with stylet (Smiths Medical, Norwell, MA, USA) under transabdominal ultrasound guidance 5 days after oocyte pickup. However, the entrance into the external cervical os was not possible. Therefore, after holding the cervix with an Allis forcep, the catheter was tried again, but failed. We tried again with a sound and it was very difficult to successfully enter. After removing the sound, we tried to enter the catheter again, but we failed, so we used a Hegar dilator of $3 \mathrm{~mm}$ diameter (Hegar number 1) to widen the entrance of the cervix. After removing the Hegar dilator, the Wallace catheter passed through the internal cervical os, but stopped at about $1 \mathrm{~cm}$ from the internal os and did not proceed further. We widened a Hegar dilator of $4 \mathrm{~mm}$ diameter (Hegar number 2) to insert the catheter using a sound as a guide. However, the sound went close to the uterine fundus, but the catheter was no longer accessible close to the internal os. Eventually, the Hegar number 1 lifted the catheter and changed direction, allowing it

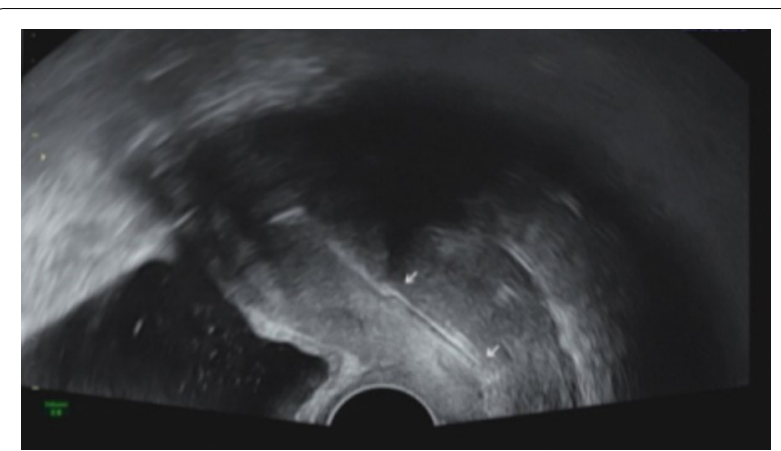

Fig. 2 Transvaginal US scan showing the Foley catheter with cotton swab inserted into cervical canal

to enter the uterus. The procedure took almost an hour. Three embryos were transferred, but pregnancy was unsuccessful.

Frozen embryo transfer (FET) started with administration of GnRH agonist (decapeptyl $0.1 \mathrm{mg}$; Ferring, Saint-Prex, Switzerland) in the mid luteal phase of the preceding cycle followed by administration of oral estradiol valerate (progynova $6 \mathrm{mg} /$ day; Bayer Schering Pharma, Berlin, Germany) daily starting on cycle-day 3. Vaginal sonography showed endometrial thickness of $8.3 \mathrm{~mm}$ with trilaminar pattern. Therefore, $\mathrm{GnRH}$ agonist was stopped and $100 \mathrm{mg}$ vaginal progesterone (Lutinus; Ferring Pharmaceuticals) two times daily was administrated until the day before embryo transfer. To facilitate embryo transfer, it was planned to use of a Foley catheter with the cotton swab after oral administration of misoprostol (Cytotec; Ali Raif, Istanbul, Turkey). After taking $200 \mu \mathrm{g}$ of misoprostol orally twice every six hours, the procedure was performed $6 \mathrm{~h}$ after taking the last misoprostol. After inserting the wooden part of the cotton swab through the bladder opening of a 13-Fr Foley catheter, when it reached the length of the cervical canal, a knot was made and the rest was cut off (Fig. 1). The Foley catheter easily passed through the cervix and stopped

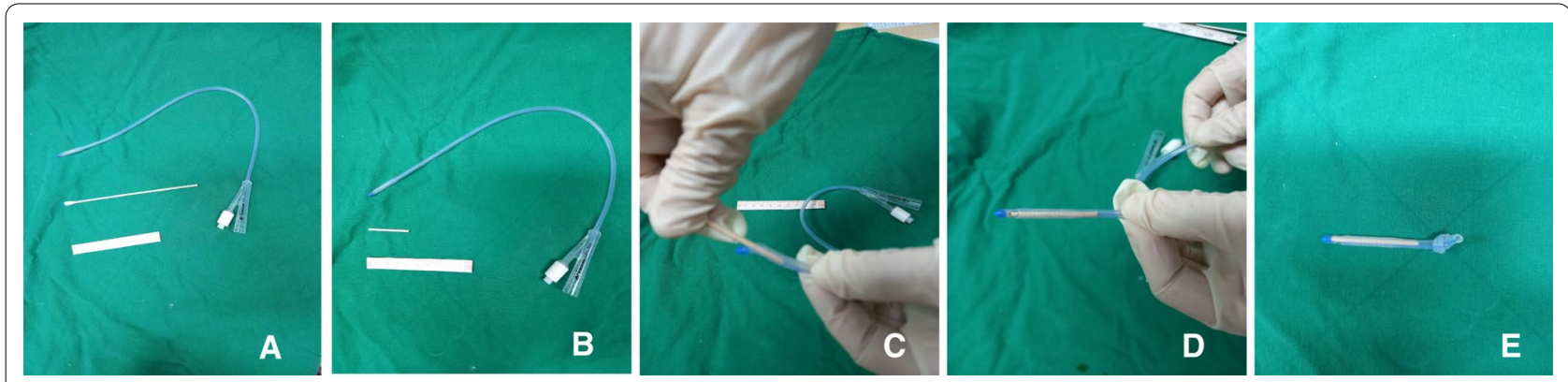

Fig. 1 The steps to make a Foley catheter with cotton swab are shown in order from left to right 
due to the knot. Transvaginal ultrasound was confirmed that the Foley catheter was well inserted from the cervix to the internal os (Fig. 2). After removing the Foley catheter after $24 \mathrm{~h}$, it was confirmed that a Hegar number 1 passed well. However, the entrance of the Wallce catheter into the uterus was not possible at the time of embryo transfer after 2 days. The same situation was repeated as in the first cycle. The embryos were difficultly transferred, but the pregnancy was unsuccessful. Magnetic resonance imaging (MRI) was performed to determine the cause of the catheter not proceeding anymore after entering the catheter $1 \mathrm{~cm}$ above the internal os. On MRI, a fibroid of about $1 \mathrm{~cm}$ in size was identified at the location (Fig. 3). After discussion, it was decided to continue the FET. The next FET was performed according to the protocol of the previous FET, but only Foley catheterization was performed 2 days before embryo transfer, and at the same time, atosiban (Tractocile; Ferring Arzneimittel, Kiel, Germany) was administered with an initial bolus dose of $6.75 \mathrm{mg}$ followed by a high dose rate of $24 \mathrm{ml} /$ hour during $3 \mathrm{~h}$ then reduced to $8 \mathrm{ml} /$ hour up to $45 \mathrm{~h}$. It had been planned that the Foley catheter with cotton swab would stay in situ and be removed immediately before embryo transfer. After removing the catheter, embryo transfer was easily performed using Cook ${ }^{\circledR}$ Sydney IVF (Cook Medical, USA). The serum hCG on day 13 after embryo transfer was at $927.2 \mathrm{IU} / \mathrm{L}$. The patient had no specific findings on antenatal care except for polyhydramnios. She delivered a healthy female baby weighing $3870 \mathrm{~g}$ by cesarean-section delivery.

\section{Discussion and conclusions}

The conventional ET procedure is usually performed by transferring embryos through the cervix. Whether a transfer catheter is smoothly introduced through the cervical canal without force or trauma up to $1-2 \mathrm{~cm}$ from the fundus is known to be an important limiting factor in pregnancy success following IVF [3-5]. Several factors related with the positive correlation of difficult ET and reduced pregnancy rates have been suggested. The presence of blood on the transfer catheter decreased the likelihood of implantation and eventually reduced pregnancy rate [6]. Goudas et al. reported that blood found outside, but not inside, the embryo transfer catheter was associated with lower embryo implantation and clinical pregnancy rates [1]. Another factor that difficult ET can decrease pregnancy rates is the stimulation of uterine contractions. Manipulating with a tenaculum to the cervix or touching the uterine fundus induces uterine contractions by secreting prostaglandins (PG) and oxytocin $[7,8]$. Fanchin et al. showed that uterine contractions at the time of ET was associated with a decrease in implantation rates and clinical pregnancy rates [9]. Wood et al. demonstrated that performance of ET with a soft catheter under ultrasound guidance increased in clinical pregnancy rates [10].

Several attempts have been made to overcome such situations as cervical stenosis, where difficult transfers are expected. These include trying with a mock or dummy embryo catheter before ET $[4,11]$, straightening the cervicouterine angle by pulling the cervix with a tenaculum or passive filling the bladder $[12,13]$, or using ultrasonographic guidance during the ET [14]. In addition, when cervical dilatation method was performed during an

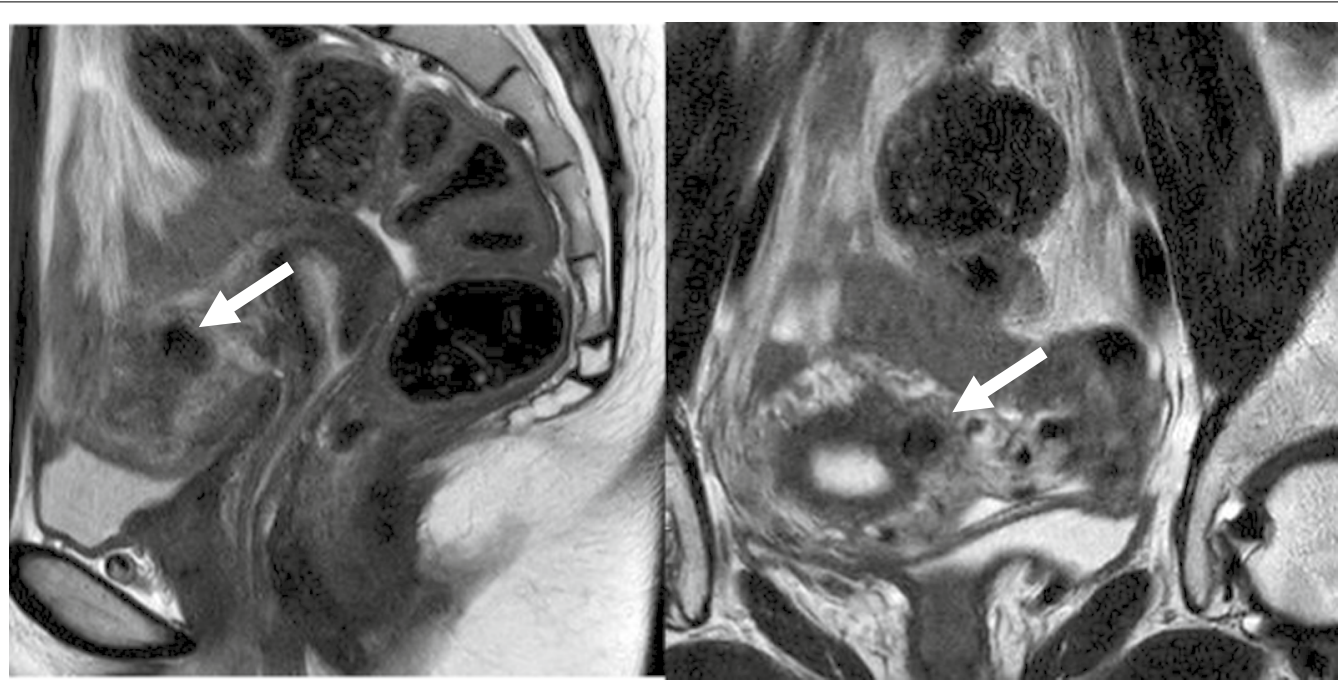

Fig. 3 MRI showing an intramural fibroid in contact with the endometrium 
ovum pick-up [15], at the initial visit in an IVF-ET cycle (approximately 2 weeks before ET) [16], 1-3 months before ET [17], or using laminaria tents [18], ET became easier and the pregnancy rate improved. Hysteroscopic revision of the cervical canal resulted in easier ET and improved pregnancy rates in patients with cervical stenosis [19]. However, although the above methods may be useful for the ET, the procedure is still difficult or impossible for some patients. Furthermore, while reporting the occurrence of uterine perforation or cervical incompetence in the cervical dilatation method, the authors reported that attention should be paid to the risks [17]. It was noted that hysteroscopic revision of the cervical canal also needed to be counseled regarding potential obstetric risks [20]. Ultrasound-guided, transmyometrial ET has been suggested as an alternative method to transcervical ET [21, 22]. However, according to the study comparing ultrasound-guided transmyometrial and transcervical ET, there was no benefit from transmyometrial ET compared to conventional transcervical ET in patients with cervical stenosis or in patients who had failed to conceive in previous cycles [23]. Another study reported that transmyometrial ET is a good alternative option in cases of very difficult transcervical ET, but its superiority over conventional transcervical ET cannot be demonstrated [24]. The limitation of this method is that it is easily affected by the location of the uterus and the accuracy of ultrasound because the success of the procedure depends on how accurately the needle through uterine wall is approached to the uterine cavity [22].

In the present case, we used a Foley catheter with cotton swab to secure enough space for the implantation catheter to fit. We did not use laminaria tents because of concerns about the possibility of intrauterine infection [18] and the possibility of uterine contraction due to excessive dilatation of the cervix. Norman et al. have shown that misoprostol increases in the amplitude and frequency of uterine contractions [25]. Also, Fanchin et al. have reported that uterine contractions can be triggered by cervical manipulation [9]. As our case, cervical manipulation such as keeping a Foley catheter in the cervical canal may also cause uterine contractions. Moraloglu et al. have suggested that atosiban treatment before ET is effective in priming of the uterus for implantation, showing that atosiban increased the implantation rate and the clinical pregnancy rate [26]. As shown in our case, it is important that the dilatation of cervix is maintained until immediately before ET, and it may be an effective method for patients with cervical stenosis to give uterine relaxant together to suppress uterine contraction.

In conclusion, we present a case of successful pregnancy in a patient with cervical stenosis using a Foley catheter with cotton swab and concurrent oxytocin antagonist before ET. In case of cervical stenosis, it is important to keep the dilatation of cervix until immediately before ET, and it is recommended to use uterine relaxant together to prevent uterine contraction. In addition, the risk of obstetric complications such as cervical incompetence may be very low by using a thin Foley catheter. Further studies are needed to prove its effectiveness.

\section{Abbreviations \\ ET: Embryo transfer; IVF: In vitro fertilization; FSH: Follicle stimulating hormone; LH: Luteinizing hormone; $E_{2}$ : Estradiol; P: Progesterone; AMH: Anti-Müllerian hormone; HSG: Hysterosalpingography; GnRH: Gonadotropin-releasing hor- mone; hCG: Human chorionic gonadotropin; FET: Frozen embryo transfer; MRI: Magnetic resonance imaging; PG: Prostaglandins; IVF-ET: In vitro fertilization- embryo transfer}

\section{Acknowledgements}

Thank numerous individuals participated in this study.

\section{Author contribution}

$\mathrm{HC}$ designed the case report and wrote the manuscript. All authors read and approved the final manuscript.

\section{Funding}

Not applicable.

Availability of data and materials

Data and material are available on request from the corresponding author.

\section{Declarations}

Ethics approval and consent to participate

This study was approved by the Ethics Committee of Jeonbuk National University Hospital (File number 2021-01-002).

\section{Consent for publication}

The patient provided written informed consent to publish her anonymous data in the present case report.

\section{Conflict of interest}

The authors declare that they have no competing interests.

Received: 15 March 2021 Accepted: 21 June 2021

Published online: 03 July 2021

\section{References}

1. Goudas VT, Hammitt DG, Damario MA, Session DR, Singh AP, Dumesic DA. Blood on the embryo transfer catheter is associated with decreased rates of embryo implantation and clinical pregnancy with the use of in vitro fertilization-embryo transfer. Fertil Steril. 1998;70:878-82.

2. Kava-Braveman A, Martínez F, Rodríquez I, Álvarez M, Barri PN, Coroleu B. What is a difficult transfer? Analysis of 7,714 embryo transfers: the impact of maneuvers during embryo transfer on pregnancy rate and a proposal of objective assessment. Fertil Steril. 2017;107:657-63.e1.

3. Wood C, McMaster R, Rennie G, Trounson A, Leeton J. Factors influencing pregnancy rates following in vitro fertilization and embryo transfer. Fertil Steril. 1985;43:245-50.

4. Mansour R, Aboulghar M, Serour G. Dummy embryo transfer: a technique that minimizes the problems of embryo transfer and improves the pregnancy rate in human in vitro fertilization. Fertil Steril. 1990;54:678-81. 
5. Tomás C, Tikkinen K, Toumivaara L, Tapainainen JS, Martikainen H. The degree of difficulty of embryo transfer is an independent factor for predicting pregnancy. Hum Reprod. 2002;17:2632-5.

6. Wood EG, Batzer FR, Go KJ, Gutmann JN, Corson SL. Ultrasound-guided soft catheter embryo transfers will improve pregnancy rates in in-vitro fertilization. Human Reprod. 2000;15:107-12.

7. Lesny P, Killick SR, Tetlow RL, Robinson J, Maguiness SD. Embryo transfercan we learn anything new from the observation of junctional zone contractions. Hum Reprod. 1998;13:1540-6.

8. Dorn C, Reinsberg J, Schlebusch H, Prietl G, van der Ven H, Krebs D. Serum oxytocin concentrations during embryo transfer procedure. Eur J Obstet Gynecol Reprod Biol. 1999;87:77-80.

9. Fanchin R, Righini C, Olivennes F, Taylor S, de Ziegler D, Frydman R. Uterine contractions at the time of embryo transfer alter pregnancy rates after in-vitro fertilization. Hum Reprod. 1998;13:1968-74.

10. Wood EG, Batzer FR, Go KJ, Gutmann JN, Corson SL. Ultrasound-guided soft catheter embryo transfers will improve pregnancy rates in in-vitro fertilization. Hum Reprod. 2000;15:107-12.

11. Knutzen V, Stratton CJ, Sher G, McNamee PI, Huang TT, Soto-Albors C. Mock embryo transfer in early luteal phase, the cycle before IVF and embryo transfer: a descriptive study. Fertil Steril. 1992;57:156-62.

12. Sundstrom $P$, Wramsby $H$, Person PH, Leidhom P. Filled bladder simplifies human embryo transfer. Br J Obstet Gynecol. 1984;91:506-7.

13. Lewin A, Schenker JG, Avrech O, Shapira S, Safran A, Friedler S. The role of uterine straightening by passive bladder distension before embryo transfer in IVF cycles. J Assist Reprod Genet. 1997;14:32-4.

14. Prapas Y, Prapas N, Hatziparasidou A, Prapa S, Nijs M, Vanderzwalmen P, Vlassis $G$, Jones EE. The echoguided embryo transfer maximized the IVF results. Acta Eur Fertil. 1995;26:113-5.

15. Groutz A, Lessing B, WolfY, Yovel I, Azem F, Amit A. Cervical dilatation during ovum pick-up in patients with cervical stenosis: effect on pregnancy outcome in an in vitro fertilization-embryo transfer program. Fertil Steril. 1997:67:909-11.

16. Abusheikha N, Lass A, Akagbosu F, Brinsden P. How useful is cervical dilatation in patients with cervical stenosis who are participating in an in vitro fertilization-embryo transfer program? The Bourn Hall experience. Fertil Steril. 1999;72:610-2

17. Prapas N, Prapas Y, Panagiotidis S, Prapa S, Vanderzwalmen P, Makedos G. Cervical dilatation has a positive impact on the outcome of IVF in randomly assigned cases having two previous difficult embryo transfers. Hum Reprod. 2004;19:1791-5.

18. Glatstein IZ, Pang SC, McShane PM. Successful pregnancies with the use of laminaria tents before embryo transfer for refractory cervical stenosis. Fertil Steril. 1997:67:1172-4.

19. Pabuccu R, Ceyhan ST, Onalan G, Goktolga U, Ercan CM, Selam B. Successful treatment of cervical stenosis with hysteroscopic canalization before embryo transfer in patients undergoing IVF: a case series. J Minim Invasive Gynecol. 2005;12:436-8.

20. Noyes N. Hysteroscopic cervical canal shaving: a new therapy for cervical stenosis before embryo transfer in patients undergoing in vitro fertilization. Fertil Steril. 1999;71:965-6.

21. Kato O, Takatsuka R, Asch RH. Transvaginal-transmyometrial embryo transfer: the Towako method; experiences of 104 cases. Fertil Steril. 1993;59:51-3.

22. Sharif $K$, Afnan $M$, Lenton $W$, Bilalis $D$, Hunjan $M$, Khalaf $Y$. Transmyometrial embryo transfer after difficult immediate mock transcervical transfer. Fertil Steril. 1996;65:1071-4.

23. Groutz A, Lessing JB, WolfY, Azem F, Yovel I, Amit A. Comparison of transmyometrial and transcervical embryo transfer in patients with previously failed in vitro fertilization-embryo transfer cycles and/or cervical stenosis. Fertil Steril. 1997;67:1073-6.

24. Khairy M, Shah H, Rajkhowa M. Transmyometrial versus very difficult transcervical embryo transfer: efficacy and safety. Reprod Biomed Online. 2016:32:513-7.

25. Norman JE, Thong KJ, Baird DT. Uterine contractility and induction of abortion in early pregnancy by misoprostol and mifepristone. Lancet. 1991;16:1233-6.

26. Moraloglu O, Tonguc E, Var T, Zeyrek T, Batioglu S. Treatment with oxytocin antagonists before embryo transfer may increase implantation rates after IVF. Reprod Biomed Online. 2010;21:338-43.

\section{Publisher's Note}

Springer Nature remains neutral with regard to jurisdictional claims in published maps and institutional affiliations.

Ready to submit your research? Choose BMC and benefit from

- fast, convenient online submission

- thorough peer review by experienced researchers in your field

- rapid publication on acceptance

- support for research data, including large and complex data types

- gold Open Access which fosters wider collaboration and increased citations

- maximum visibility for your research: over 100M website views per year

At BMC, research is always in progress.

Learn more biomedcentral.com/submissions 